revival of suprapubic cystostomy which has already been expressed here as well as in the United States, and I deplore such an approach which ignores so profoundly the natural forces of the physiological adjustment of the neurogenic bladder in the spinal man. In my opinion, this procedure is a grave mistake and represents a serious retrograde step, particularly in the early management but also in the late management of paraplegics and tetraplegics as it adds a local damage to the bladder wall to the neurogen ic dysfunction of the bladder. It will result in most if not all of the unhappy consequences of suprapubic cystostomy of 25 years ago and will create a very serious situation if this surgical procedure is followed up by other workers with only little experience in the field of paraplegia and tetraplegia.

\title{
RADIOLOGICAL STUDY OF THE VESICAL NECK IN PARAPLEGIA SECONDARY TO SPINAL CORD INJURY
}

\author{
By Professor R. R. Ascoli \\ Milan
}

I INTEND to deal today with a special aspect of urology in the paraplegic, an aspect of great importance because of its repercussions on micturition, namely the behaviour of the bladder neck during micturition. I shall also consider the therapeutic implications.

Micturition is, essentially, a conflict between the expulsive forces (contraction of the detrusor muscle of the bladder and straining with the abdominal muscles) and the inhibitory forces of the sphincter complex. Clearly, the stronger the former and the weaker the latter the more easily will urine be passed. Obviously, many factors affect expulsion, namely:

(I) the capacity of the bladder, that is, the quantity of fluid it contains;

(2) the degree of vesical tone;

(3) the ability of the detrusor muscle to contract, and the extent of its contractions, that is the ability of the detrusor to contract sufficiently to empty the bladder completely;

(4) the ability of the bladder neck to open in synchrony with the contraction of the detrusor;

(5) the ability of the external sphincter to relax or to contract;

(6) the passive resistance set up by the urethral canal regardless of the sphincters, the degree of this resistance and its consequences, which differ greatly between men and women.

My subject today is point (4).

Taking advantage of the large clinical material of the Milan Orthopaedic and Traumatology Centre, we set out to study the behaviour of the bladder neck in paraplegics.

We asked ourselves the following questions:

(I) How does the bladder neck behave in paraplegics with spinal cord injury, especially during micturition? How is its behaviour respectively in patients with low, medium and high-level lesions?

(2) How does the behaviour of the bladder neck in the recently injured compare with that in patients with old injuries? 
We felt that radiology afforded the best and most physiological approach to study of the behaviour of the bladder neck. Discarding the retrograde urethro cystographic technique, which is open to considerable criticism, we chose th micturition technique because the conditions in which it is applied are very clos to normal conditions.

$A$ priori there were three possibilities:

(I) the neck might open little or not at all;

(2) it might behave more or less normally;

(3) it might be, for some reason, dilated.

At this point I will go back a few decades, to a time when it was believed that the impediment or obstacle to the expulsion of urine necessarily lay at bladder-neck level, and that the nature of this obstacle was spasticity or inability to open. On this assumption some authors proposed to diminish this resistance by resorting to transurethral resection of the neck, the technique of which has meanwhile been improved and applied to many urological conditions. And so a great number of papers appeared on the feasibility and clinical results of transurethral resection in the most varied forms of 'neurogenic bladder'. Of those who have studied this subject the most outstanding are the American Emmett and his school. According to him and to numerous other authors, in practically all forms of neurogenic bladder secondary to injury, transurethral resection of the bladder neck is indicated and the results are highly satisfactory. Emmett and his co-workers started from the assumption that the hindrance to the expulsion necessarily lay at the level of the neck. Emmett has published a large number of papers on this subject, but many of them go over the same ground. I have read most of them, and have reached the conclusion that they are vitiated (as Emmett himself, to some extent, admits), mainly by the following factors:

(I) His clinical material consisted to a large extent of persons over 50, an age at which there are chances that prostatism may be present simultaneously (this was actually found in several of Emmett's cases). Now, it is well known that transurethral resection is beneficial in prostatism.

(2) There were practically no X-ray check-ups, i.e. no urethro-cystograms, either pre- or post-operative. And this is rather a big omission.

I feel that the correct and reasonable course, before proceeding to surgery of the bladder neck would have been to establish that the impediment lay clearly in the neck, particularly as this question of urethro-vesical physiopathology is not difficult to be answered radiologically by the voiding urethro-cystogram technique, which enables us to study micturition in conditions that are very nearly physiological.

We decided to carry out a very large number of voiding urethro-cystograms in paraplegics, selecting a wide range of cases as regards duration of the spinal cord lesion, level of the lesion, patient's age and so on.

We have divided our patients into five grades according to the radiological appearance of the bladder neck and compared with a normal vesical neck as shown in Figure I. normal.

Grade I comprises cases in which the neck seemed to be narrower than 
Grade II consists of cases in which the neck and posterior urethra presented a more or less normal appearance, i.e. the neck was slightly open like an acuteangled funnel and the urethra relaxed throughout its course and not dilated.

Grade III comprises cases in which

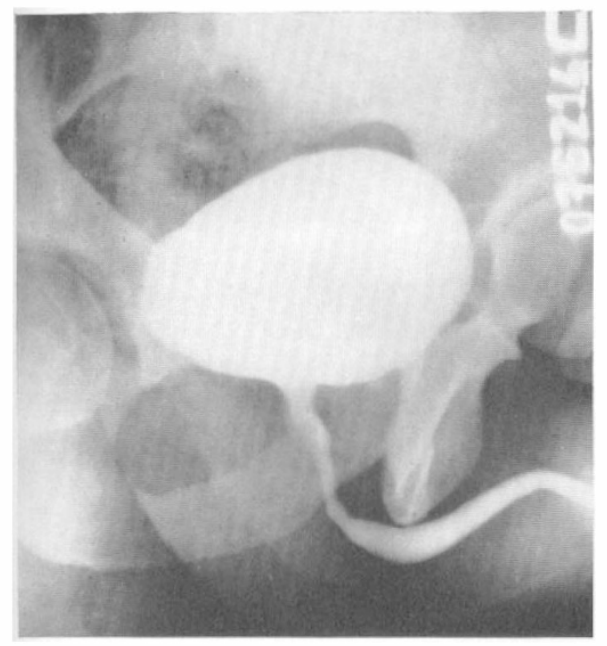

FIG. I

Normal urethra. Voiding cystogram. the neck was wide open, like an obtuseangled funnel or was shaped like a cylinder; the posterior urethra was dilated up to twice its normal calibre (Fig. 2).

Grade IV consists of cases in which the neck was gaping, and the posterior urethra had a calibre of more than twice the normal (fig. 3).

Grade $V$ comprises cases in which the posterior urethra and vesical neck were so dilated that it was difficult to distinguish bladder from urethra (vesicalisation of the prostatic urethra).

Another aspect to which we paid particular attention, in view of its peculiar significance, was the appearance of the zone of the urethra corresponding to the external sphincter.

We studied, in all, 55 cases. We considered the morphological aspect (Grades I to V), patient's age, level of lesion, the time elapsing between the date of injury and the date of examination, and the presence or absence of narrowness due to contraction by the external sphincter.

We thought it would be

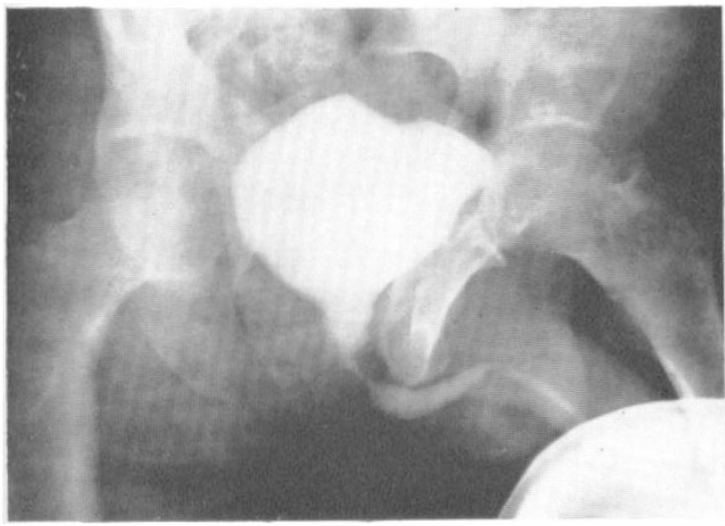

FIG. 2

Urethra of paraplegic subject. Voiding cystogram funnel shaped and dilated vesical neck. The region of external sphincter is contracted. useful to group the cases as follows:

by age-under 20,20 to 40 and over 40;

bylevel of thelesion-cervical, dorsal or lumbar; and by

age of the lesion-under 6 months, from 6 months to 2 years and over 2 years.

Results. The great majority of the vesical necks which we studied belonged to Grades III and IV ( 35 cases), i.e. with more or less pronounced dilatation. Only in I4 cases could the neck be regarded as normal. Only in three cases did the neck appear to be narrower than normal. In three cases both neck and prostatic urethra were enormously dilated. Thus, in the great majority of cases (69 per cent.) the neck 
was dilated to a greater or lesser degree. In 25 per cent. of the cases the neck presented a more or less normal aspect during micturition. Only in 5.4 per cent. of the cases was the neck narrower than normal. We felt it would be highly relevant and helpful to study the correlations between age-group, level of the lesion and age of the lesion. But careful analysis of our data convinced us that there was no correlation whatsoever between the grade of the anatomical lesion and the history we had taken.

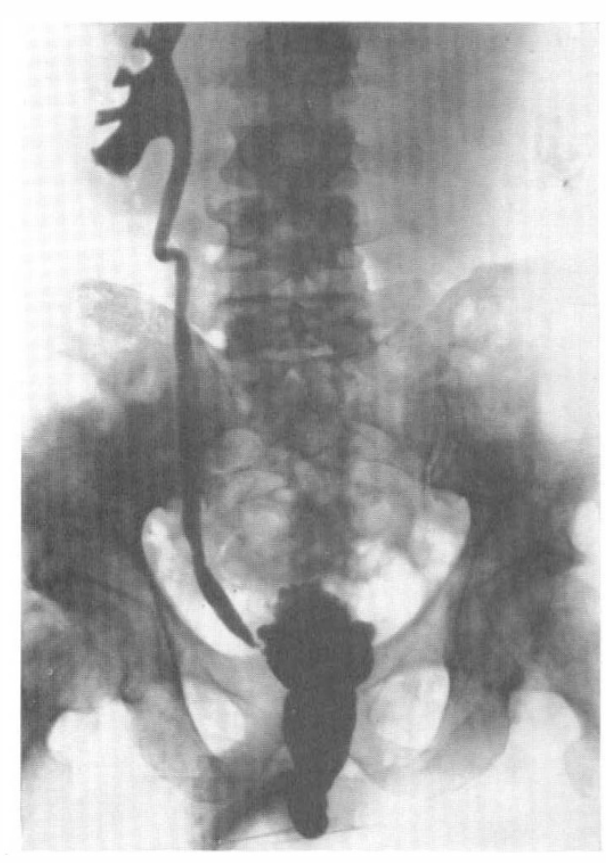

FIG. 3

Voiding cystogram in paraplegic subject. Enormous dilatation of vesical neck and of posterior urethra (vesicalisation of posterior urethra). Vesico-ureteral reflux.

The results of our investigation have their relevance to therapy, especially to the question of whether the practice of indiscriminate transurethral resection in neurogenic bladders in general and in spinal cord bladders in particular is justified or not. I feel we can say, quite definitely, not. Whilst it makes sense to widen a constricted or hardened bladder neck, there is no sense at all in resecting a neck that opens properly during micturition. Everything suggests that in the great majority of paraplegics the main obstruction lies in the external sphincter, as shown in our observation that in 48 out of 55 cases the external sphincter zone was constricted by marked hypertonus or contracture and that the dilated urethra zone began immediately above.

What are the practical conclusions of our study and what are the therapeutic implications?

(I) In the greatmajorityof paraplegics the vesical neck opens normally during micturition or more than normally.

(2) In the great majority of paraplegics the posterior urethra is dilated, often considerably.

(3) In the great majority of cases the urethro-cystographic pattern indicates that the cause of the dilatation of the posterior urethra and of the bladder neck lies lower down, at the level of the external sphincter. The phenomenon cannot be explained otherwise than in terms of spasticity or at all events, of contracture of the external sphincter during micturition.

(4) Hence the main cause of the impediment to the passage of urine does not lie at the neck and does not consist in a defect in the opening of the neck but in a contracture of the external sphincter, which does not relax in synchrony with the detrusor during micturition.

(5) Transurethral resection of the vesical neck in cases in which the neck is dilated is illogical and altogether contra-indicated. If surgery is attempted at all, the level of attack should be the external sphincter. 
Before deciding to operate and before resecting the neck it is vital to do a voiding urethro-cystogram. If the neck proves to be constricted and opens with difficulty resection may be contemplated, but if the neck and posterior urethra are dilated then resection is totally irrelevant.

\section{Discussion}

Cosbie Ross (England). Naturally, I have been very interested in Professor Ascoli's paper and I would like to congratulate him on this very important and careful study. As he has pointed out, many of his cases show the dilated posterior urethra and some even show that the obstruction is so severe that there is some cavitation of the prostatic ducts, something which we showed some years ago. I am naturally also very pleased that some of the blame is now being attached to the external sphincter-something which I have thought for many years. I think that the main lesson that Professor Ascoli has pointed out to us is that it is important to determine the level of the obstruction. It may be at the bladder neck, as Emmet has pointed out, but in many cases it is the lower level and in the region of the external sphincter. I do hope that Professor Ascoli will continue this very important and detailed study.

Bardot (France). I would like to ask Professor Ascoli whether this contracture of the external sphincter has been observed in spastic or flaccid lesions.

Ascoli. All types. My cases have not been chosen especially-all types-high lesions, mid lesions and low lesions. We have not seen remarkable differences in the cases with high, middle or low lesions.

Walsh (England). Professor Ascoli, you mention that there is no difficulty in getting a good micturating cystogram in all your cases. One of the difficulties we have found here is that in the kind of case where you really want to know what the bladder neck is like it is often extremely difficult to get micturition on the X-ray table. Have you any particular methods for ensuring micturition in these cases for the $\mathrm{X}$-ray?

Ascoli. I must say that, in the beginning, I did not know if I would be able to find a technique. Naturally, in the first stage of bladder paralysis it is impossible, as we all know, that the bladder is atonic. After about two months, when the natural contractions of the bladder begin, we try the following technique. We put a certain quantity of opaque liquid in the bladder, from 200 to $300 \mathrm{ml}$., and then the patient always succeeds in passing. If he does not succeed, we make an injection of Doryl. I must say in 99 per cent. of cases I succeed. I do not succeed in a small minority of cases, particularly not paraplegics, but with neurogenic bladders due to cauda equina lesion following operations on the rectum or after gynaecological operations; in those cases it is more difficult and in tabes dorsalis it is also difficult. In tabes dorsalis I do very often resection of the neck, and in this condition I find this operation very useful. Lately, I have operated on a case three weeks ago and had a fantastic result.

Rossier (Switzerland). Professor Ascoli, you have been speaking much about the level of the lesion. I would like to know if you have been examining your patient with regard to extent of the lesion, because I think it is fairly important to know whether you have a complete or incomplete lesion, especially if we are speaking in terms of epi-conus lesions. We know that when you have incomplete lesions, in quite a few instances we have more difficulty to rehabilitate the bladder. Have you observed in these incomplete cases possibly more contraction of the external urethral sphincter than in complete lesions? 
Ascoli. I have not chosen particular cases. They were cases of all kinds. Naturally, in my paper, when it is published, there will be all these particulars. Naturally the cases of partial lesions recover better and it is much easier to obtain good results than in complete lesion, but also in complete lesions, especially in not very low lesions We know low lesions of the cauda equina are the worst of all. Generally, we succeed in obtaining micturition, and we have these good results with re-education of the bladder.

\begin{abstract}
Zimmermann (Belgium). What do you think about the action of Doryl on the external sphincter?

Ascoli. Thre is no action on the sphincter. There is a formidable action on the detrusor muscle. Naturally, when the sphincter is very spastic this action is not so evident, but in general, with those drugs such as Doryl the effects on the contraction of the detrusor muscle are very strong.
\end{abstract}

Zimmermann. With a doctor in Liège I have studied the action of Doryl on the external sphincter by electromyography. We asked a patient with a normal sphincter to contract the sphincter (slide), then gave $5 \mathrm{mg}$. of Doryl intramuscularly and did an electromyogram 15 minutes later demonstrating the increased contractions. We gave then a spasmolytic drug intravenously and the results were fewer contractions as compared with those following Doryl injection.

Sir Ludwig. It struck me that in some of your cases there were fistulae or diverticula of the urethra. Would you be good enough to tell us the percentage in your cases of diverticula and fistula in paraplegia?

Ascoli. The cases I showed were all treated in other hospitals and came to us later. I can say that I always use Jacques catheters of small size, never more than Jacques I2, so this is the cause why we have very little diverticula and fistulae.

\title{
ELECTROMYOGRAPHY IN SPINAL CORD LESION WITH SPECIAL REFERENCE TO THE SPHINCTERS
}

\author{
By \\ Alex Chantraine \\ Laboratory of Physiotherapy, Hôpital de Bavière \\ and \\ Leo Timmermans \\ Urological Clinic, University of Liège
}

ElECTROMYOGRAPHY study in spinal cord lesion presents a certain interest according to the aetiology of the paraplegia. This assessment may greatly help to make the diagnosis in poliomyelitis, polyradiculo-neuritis (Guillain-Baré) or cauda equina compression. It may also give valuable information about the level of the lesion in traumatic paraplegia and in spina bifida with myelomeningocele.

Furthermore, we have found that its more valuable indication is the informa tion it gives in the exploration of the striated sphincters (anal and urethral). In paraplegia, electromyography study of the sphincters may give detailed informa tion and precision; also it completes data yielded by other investigative techniques. 